\title{
Injecting Drug Users Retention in Needle-Exchange Program and its Determinants in Iran Prisons
}

\author{
Mohammad Shahbazi ${ }^{1}$; Marzieh Farnia ${ }^{2}$; Ghobad Moradi ${ }^{3,4}$; Mohammadreza Karamati ${ }^{5}$; \\ Fatemeh Paknazar ${ }^{6}$; Majid Mirmohammad Khani ${ }^{7,,^{*}}$ \\ ${ }^{1}$ United Nations Development Program, Prisons Organization, Tehran, IR Iran \\ ${ }^{2}$ Health and Treatment Office of Iranian Prisons Organization, Tehran, IR Iran \\ ${ }^{3}$ Social Determinant of Health Research Center, Kurdistan University of Medical Sciences, Sanandaj, IR Iran \\ ${ }_{5}^{4}$ Epidemiology and Biostatistics Department, Faculty of Medicine, Kurdistan University of Medical Sciences, Sanandaj, IR Iran \\ 5 Epidemiology and Biostatistics Department, Faculty of Medicine, Kurdistan Un \\ 6 Department of Surgery, Tehran University of Medical Sciences, Tehran, IR Iran \\ ${ }_{7}^{7}$ Department of Epidemiology and Biostatistics, School of Public Health, International Campus, Tehran Univers \\ ${ }^{8}$ Community Medicine Department, Faculty of Medicine, Semnan University of Medical Sciences, Semnan, IR Iran \\ ${ }^{*}$ Corresponding author: Majid Mirmohammad Khani, Community Medicine Department, Faculty of Medicine, Semnan University of Medical Sciences, Semnan, IR Iran. Tel: \\ +98-2313354183, E-mail: majidmirmohammadkhani@yahoo.com, mirmohammadkhani@razi.tums.ac.ir
}

Received: September 19, 2014; Revised: December 15, 2014; Accepted: December 17, 2014

\begin{abstract}
Background: Participation and to stay in a health program depends on many factors. One of these programs is Needle Exchange Program (NEP) in prisons.

Objectives: The current study aimed to evaluate the retention of injecting drug prisoners and find the related factors in Iran.

Patients and Methods: This cohort study analyzed data about injecting drug male prisoners who were participated in NEP in three Iranian prisons. Data was collected from October 2009 to June 2010. A proper approach of survival analyses including Kaplan-Meier method, LogRank test, and Cox Proportional Hazard Model were used to evaluate Injecting Drug Users (IDUs) retention in NEP and its determinants. Results: Out of 320 prisoners, 167 were from Isfahan Central Prison, 82 from Tehran-Ghezel-Hesar Prison, and 71 from Hamadan Central Prison. Two-hundred and fifty prisoners (78.4\%) had history of drug injection; and drug injection was the most common choice for 115 persons (35.9\%). Participants were followed up for 29 weeks, the mean (SD) time of retention in the program was 24.1(0.6) weeks. There was a significant relationship between age, number of used needles per week, duration of addiction, age of addiction onset, as well as imprisonment age, main method of drug use, type of main using drug, Hepatitis B Virus (HBV) infection, job status, reason of arrestment, history of involvement in harm reduction programs, and the length of retention $(\mathrm{P}<0.05)$. There was also significant relationship between the history of using harm reduction services $(\mathrm{P}=0.007)$, tattooing $(\mathrm{P}=0.01)$, longer durations of addiction $(\mathrm{P}=0.048)$, and retention.

Conclusions: Tattooing and longer duration of addiction were two important factors that significantly increased retention in the program. In contrast, history of using harm reduction services was the factor that decreased persistence. The risk of quitting the program may decrease about $68 \%$ in those who did not involve in harm reduction programs.
\end{abstract}

Keywords: Needle-Exchange Program; Prisons; Iran

\section{Background}

Using shared needles and syringes for intravenous drug injection not only is an important Human Immunodeficiency Virus (HIV) risk factor, but also increases Hepatitis B Virus (HBV) and Hepatitis C Virus (HCV) transmission (1). The incidence and prevalence of HIV among Injecting Drug Users (IDUs) in some parts of the world is increasing (2-4) and HIV is epidemic in 110 countries so far (5). In seven out of ten areas under the coverage of the joint United Nations programme on HIV and AIDS (UNAIDS), i.e. about $90 \%$ of the world population, intravenous drug injection is the first (or second) cause of HIV transmission (6, 7). High prevalence rates of HBV and HCV among IDUs represent the vulnerability of this population (8); the chance of HCV infection among those with history of intravenous injec- tion is 53 times more than normal people(9). These diseases can spread among IDUs easily and then be transmitted to other groups of society via sexual relationships.

The main strategy to control the mentioned diseases among IDUs is to perform harm reduction programs; Needle-Exchange Program (NEP) is one of the main harm reduction activities. Availability of sterile needles and syringes reduces the risk of HIV and hepatitis transmission and decreases the high risk behaviors, which can lead to transmission $(7,10)$. Limited access to syringes and needles increases the probability of shared injection $(11,12)$. Another advantage of this program is finding new chances to counsel and train IDUs as a part of program administration; it can decrease the prevalence of dis- 
eases (13). Nowadays the developed countries take advantage of NEP as an important approach to control HIV and hepatitis among IDUs (14); therefore, some consider this program as the best strategy to reduce HIV prevalence among IDUs (15). Compared with the general society, intravenous drug injection is more probable in prisons, because there are more drug users (16). Some studies show that more than half of IDUs continue their drug use habits during the period of imprisonment (17). Consequently, the mentioned infectious diseases can become more prevalent in prisons and then be transmitted to the society, undesirably $(18,19)$. European prisons have practiced NEP for a long time and it has proved successful and cost effective; since it had its good outcomes, Spanish governors decided to conduct NEP program in all prisons (12).

Based on the most recent statistics reported by Iran ministry of health, more than $60 \%$ of new HIV cases are IDUs. HCV and $\mathrm{HBV}$ are two other common diseases among this population. Some other statistics say more than $50 \%$ of prisoners in Iran are drug users and addiction is the most important cause of incarceration in this country. The reports about drug detection in prisons can illustrate high prevalence of drug use in prisons. Many prisoners are either drug users or they are arrested because of drug trafficking (20).

NEP has always been a controversial issue for policymakers and usually prison staffs are against the program; therefore, this program did not last very long in some countries. For example, three NEP projects in Hamburg prisons, Germany, stopped after six years. Despite the World Health Organization (WHO) emphasis to run NEP in all prisons, most prisons in all parts of the world prefer abstinence strategies and consequently NEP is limited. One of the probable reasons is the scarcity of the studies focusing on successful aspects of NEP. Most of the conducted studies did not introduce comprehensive and precise methods and measures to assess the effects of NEP; lack of reliable methods to assess the effects of NEP and lack of practical and appropriate evaluation measures are mentioned as limitations in many of these studies. As a result, NEP is not performed with a unique approach in prisons located in different parts of the world and many countries have introduced this program just to a limited number of prisons as a pilot program (19). Some studies in the European countries demonstrated the efficacy of NEP in controlling infectious diseases; however, a limited number of studies are conducted out of Europe on the same subject. It is recommended to conduct more practical studies in Asian and Middle Eastern countries (21). Such studies must assess different aspects of the program like efficacy and impacts of the program. Short retention of IDUs in the program has always been a barrier to the success of the program. In a study conducted to assess and evaluate NEP, a higher chance of involvement in the program is considered as an important measure to evaluate the program (22). Accordingly, the retention of people in the program can be considered as a measure to assess the chance of involvement of target groups in the program. Hence, longer retention in the program increases the chance of benefit from the program and it can represent its success.

In many countries, prisons are places for the transmission of HIV and HCV. Although people who inject drugs may inject less frequently while incarcerated, the risks of injection drug use are amplified because of the scarcity of sterile syringes and sharing the injection equipment in prison. Prison needle-exchange was started by physicians in Switzerland 20 years ago in 1992, and now is continued in 60 prisons around the world from Germany and Spain to Kyrgyzstan and Iran. Needle-exchange in the prisons of Iran is part of an overall harm reduction approach to drugs, which seeks to make drug use less deadly to the addict and to diminish the crime and disease that drug addiction causes. In this program drug addicts are given clean needles simply on request. Making sterile injection equipment available to people in prison is an important response to evidence of the risk of HIV and HCV transmission through sharing syringes to inject drugs (23).

It is necessary to train the healthcare staff and the community concerning preventive measures such as methadone maintenance therapy, to reduce harm for substance drug users (24). Although some studies focused on the retention of addicted people in methadone maintenance therapy, there was no study on assessing the retention of addicted prisoners in NEP and its related factors (25). Identifying factors affecting people retention in harm reduction programs could be helpful and advantageous in designing a more sophisticated model for the program. Retention in the program can be considered as a good measure for the region as well. Iran is among the countries which did not administer NEP in all of its national prisons. However, in line with the instructions of international organizations, this program was administered in some of Iran's prisons as a pilot program from 2008 to 2010.

\section{Objectives}

The current study aimed to measure the retention of IDUs prisoner in this program and to find the related determining factors.

\section{Patients and Methods}

The current cohort study, which used the data about addicted prisoners in Iran, registered from October 2009 to June 2010. The population included all male addicted prisoners under the coverage of NEP program (in a period of 29 weeks) incarcerated for different reasons in one of the three prisons of Tehran-Ghezel-Hesar, Hamadan Central Prison, and Isfahan Central Prison. The prisoners' information including demographic features (age, marital status, level of education); history of arrestment or incarceration (the number of imprisonments, the duration of the most recent imprisonment, and the duration of all imprisonments); history of drug use, treatment and high risk behaviors (main used drug, age of 
injection onset, duration of addiction, history of using shared needles, history of addiction treatment, number of injections per week, number of used needles per week, number of injections using shared needles per month, history of drug intoxication, unsafe sexual behaviors, tattooing); and approving the NEP program by the prisoner, were collected via self-declarative interviews at the time of entrance of prisoners to the program registered in special data-gathering forms kept in the prisoners' profiles. Other information included HIV/HBV/HCV infections confirmed serologically only in the participants who volunteered to give blood samples. The prisoners were followed up weekly; if a prisoner was willing to abandon the program, the supervisors of the program recorded the reasons (such as personal decisions, transfer, releasing, or death). All the participants were ensured about confidentiality of their private information. The prisoners were free to keep on or abandon the program. A written consent letter was signed by each prisoner to be included in the study. It is noteworthy that participation in the program was completely voluntary and there was no pressure on the prisoners in any of the stages of the plan and data gathering. The variable analyzed in this study was the length of prisoners ' retention in the program, from the time of entrance to the program until the time of quitting the program because of disinclination. A proper method of survival analysis was used to analyze the data. Analysis was conducted in three steps. First, categorical variables were analyzed separately using KaplanMeier and Log-Rank tests; then, the relationship between numerical variables and retention length was analyzed using Simple Cox Proportional Hazard Model; and as the final step, all numerical and categorical variables related to retention in the program ( $\mathrm{P}$ value $<0.2)$ were put in Multiple Stratified Cox Proportional Hazard and after achieving the final model, using Backward Approach and via Likelihood Ratio Test, Adjusted Hazard Ratio was calculated for the mentioned variables.

The goodness-of-fit testing approach was used to check the Proportional Hazards ( $\mathrm{PH}$ ) assumption, meaning that the hazard ratio is constant over time. The related tables represent the program exit hazard ratio and other statistical factors, which are related to retention length in each level of analysis. The first step of analysis was done via SPSS software ver.16, and the second and third steps were analyzed via STATA software ver. 9.2. The confidence interval of $95 \%$ was used for all statistical analysis approaches.

\section{Results}

Out of 320 inmates, 167 (52.2\%) were from Isfahan Central, 82 (25.6\%) from Tehran-Ghezel-Hesar, and 71 (22.2\%) from Hamadan Central prisons. They were all male with the history of drug use. Their mean age was $34.2 \pm 7.8$ years, ranging from 21 to 63 years old. Two hundred and thirty three subjects (69.7\%) were imprisoned because of drug trafficking and other participants were arrested for other reasons. The mean of imprisonment duration was $1618.2 \pm$
1491.6 days, and the mean of drug use duration was $15.5 \pm$ 8.3 years. Two hundred and fifty one prisoners (78.4\%) had history of drug injection; heroin and crack were the first choice among 247 subjects ( $81.2 \%$ ), and drug injection was the most common using method among 115 ones (35.9\%).

Figure 1 indicates the survival function in terms of retention of prisoners, using Kaplan-Meier Curve. Out of the prisoners participating in the pilot program, 48 subjects (15\%) quitted the program due to personal considerations (failure cases) and the others abandoned the program for other different reasons (censored cases). The mean time of retention in the program was $24.1 \pm 0.6$ weeks.

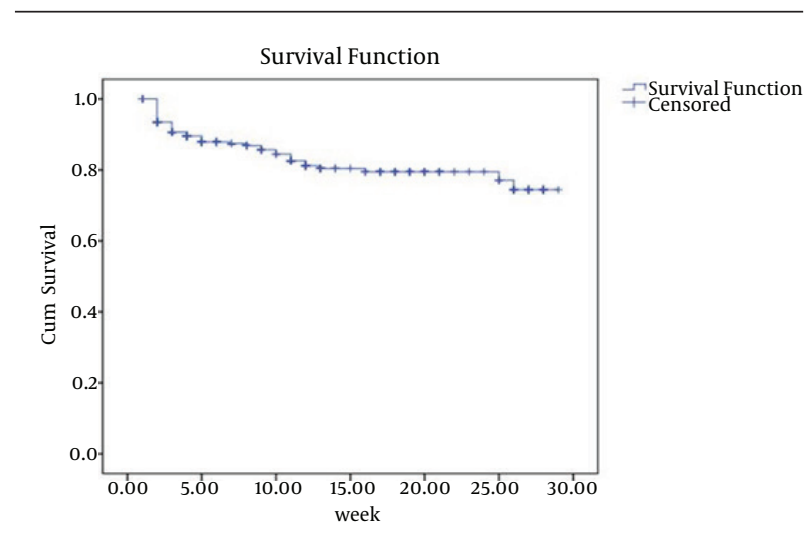

Figure 1. Kaplan-Meier Curve for the Duration of Retention in NEP Program in Iranian Prisons

Table 1 indicates the estimated means and standard deviations for retention per week based on those categorical variables that had significant relationship with retention. As presented, prison, main method of drug use, type of main using drug, HBV infection, occupation, reason of arrestment, and any history of involvement in harm reduction programs were among the stratified variables that were significantly related to the length of retention $(\mathrm{P}<0.05)$.

However, marital status $(\mathrm{P}=0.7)$, level of education $(\mathrm{P}=$ $0.8)$, history of high risk sexual behaviors $(\mathrm{P}=0.6)$, tattooing $(\mathrm{P}=0.1)$, history of using shared needles $(\mathrm{P}=0.1)$, HIV infection $(P=0.1)$, HCV infection $(P=0.1)$, drug intoxication $(\mathrm{P}=0.2)$, approving the program by the prisoner ( $\mathrm{P}$ $=0.1)$, and history of addiction treatment $(\mathrm{P}=0.2)$ were the categorical variables without any significant relationship with the length of retention.

According to Table 2, there was a significant relationship between the calculated Crude Hazard Ratio for quitting the program in a confidence interval of 95\% for all numerical variables entered in the Multiple Stratified Cox Proportional Hazard Model and retention; also significant relationship between longer durations of addiction $(P=0.03)$ and retention in the program was found. However, there was a significant relationship between age increase, number of needles used per week, duration of addiction, addiction onset age and retention in the program reversely in terms of crude hazard ratios $(\mathrm{P}<0.05)$. 
Shahbazi M et al.

\begin{tabular}{|c|c|c|}
\hline Variable & Retention, $\mathbf{w k}^{\mathrm{a}}$ & P Value $^{b}$ \\
\hline Prison & & $<0.001$ \\
\hline Isfahan & $23.5 \pm 0.9$ & \\
\hline Hamadan & $11.3 \pm 1.0$ & \\
\hline Tehran & $26.4 \pm 0.3$ & \\
\hline Drug injection & & 0.008 \\
\hline Yes & $25.9 \pm 0.7$ & \\
\hline No & $21.9 \pm 0.8$ & \\
\hline Main used drug & & 0.001 \\
\hline Opium/opium extract & $18.6 \pm 3.1$ & \\
\hline Heroin and crack & $24.6 \pm 0.6$ & \\
\hline Ecstasy & $25.9 \pm 1.0$ & \\
\hline Other drugs & $9.8 \pm 0.9$ & \\
\hline HBV test & & 0.02 \\
\hline Negative & $25.0 \pm 0.6$ & \\
\hline Positive/unknown & $23.1 \pm 0.8$ & \\
\hline Occupation/income & & 0.05 \\
\hline Stable job / regular income & $22.7 \pm 1.1$ & \\
\hline Instable job / irregular income & $24.1 \pm 0.6$ & \\
\hline Main cause of imprisonment & & $<0.001$ \\
\hline Drug-related crime & $25.8 \pm 0.6$ & \\
\hline Crimes not related to drugs & $18.4 \pm 1.5$ & \\
\hline History of involvement in harm reduction programs & & $<0.001$ \\
\hline Yes & $19.9 \pm 1.2$ & \\
\hline No & $25.7 \pm 0.6$ & \\
\hline
\end{tabular}

\begin{tabular}{lcccc}
\hline Table 2. Crude Hazard Ratios for Quitting the Program for Numerical Variables Entered in a Simple Cox Proportional Hazard Model \\
\hline Variable & Crude Hazard Ratio & 95\%Conf. Interval & \multirow{2}{*}{ P Value } \\
\cline { 3 - 4 } & & Upper & Lower & 0.002 \\
\hline Age, $\mathbf{y}$ & 0.930 & 0.974 & 0.887 & 0.003 \\
Number of used needles per week & 1.022 & 1.038 & 1.007 & 0.03 \\
Duration of addiction, $\mathbf{y}$ & 0.953 & 0.997 & 0.912 & 0.03 \\
\hline Age of injection onset, $\mathbf{y}$ & 0.959 & 0.996 & 0.924 & \\
\hline
\end{tabular}

However, there was an insignificant relationship between the number of injections per week $(P=0.4)$, injections using shared needles per month $(P=0.1)$, imprisonments $(\mathrm{P}=0.5)$, the duration of the most recent imprisonment $(P=0.1)$, the duration of all imprisonments $(P=0.8)$ and retention in the program.

According to Table 3, there was a significant relation- ship among the Adjusted Hazard Ratio in a confidence interval of $95 \%$ for the remaining variables in the final Multiple Model. As presented in this table, a significant relationship was observed between the variables entered in the model, history of not using harm reduction services $(P=0.007)$, tattooing $(P=0.01)$, longer durations of addiction $(\mathrm{P}=0.048)$, and retention in the program. 
Shahbazi M et al.

Table 3. Adjusted Hazard Ratios for the Remaining Variables in the Final Model of Multiple Stratified Cox Proportional Hazard ${ }^{\text {a }}$

\begin{tabular}{lccccc}
\hline Variable & Adjusted Hazard Ratio & \multicolumn{2}{c}{ 95\%Conf. Interval } & \multirow{2}{*}{ PValue } \\
\cline { 3 - 4 } & & Upper & \multicolumn{2}{c}{ Lower } \\
\hline Without history of drug treatment & 0.657 & 1.466 & 0.294 & 0.3 \\
Without history of involving in harm reduction programs & 0.324 & 0.736 & 0.142 & 0.007 \\
Tattooing & 0.453 & 0.879 & 0.233 & 0.01 \\
Duration of addiction, $y$ & 0.937 & 1.00 & 0.877 & 0.048 \\
\hline Age of addiction onset, $y$ & 0.965 & 1.02 & 0.909 & 0.2 \\
\hline Imprisonment for drug trafficking & 1.266 & 2.709 & 0.591 & 0.5 \\
\hline
\end{tabular}

a Stratified by Prisons.

\section{Discussion}

The current study assessed the retention length of IDU prisoners in NEP in a time interval of 29 weeks and analyzed the factors affecting retention. Based on the findings, three-fourth of the participants remained in the program; therefore, the average retention duration was 24.1 weeks. The authors believe that this length of retention can be a sign of success of program in Iran prisons. Nonetheless, there was no other study assessing the retention of IDU prisoners in NEP program in Iran to compare the results and findings with.

The prisoners in Tehran, and Hamadan had the longest and the shortest retention time, respectively. Probably, the differences in managing the program and the insight and reactions of prison managers and staffs caused such differences. The differences in the type of prisoners in these three prisons might be effective as well. Primary analysis showed that the subjects imprisoned for drug trafficking had longer retention periods; these factors lost significance in the final model. This issue could be attributed to the non-equal distribution of subjects in the three prisons. Most of the subjects in Tehran were arrested for drug trafficking. Previous studies noted that the dominant culture and condition in each prison can affect the results of NEP program (26). It is suggested to conduct further studies on this regard.

The common used drug and the common method of using drug were among the factors that affected retention in the program; ecstasy users had the longest retention, and then heroin and crack addicts were the next most persistent ones in the program. Moreover, those who used drug injection as the most common method of drug use, showed more persistence in the program. These subjects were dependent on more kinds of substances or they had more chronic types of addiction. These variables had no significant relationship in the final analysis; however, tattooing was significantly related to retention in the final model. It might be said that those who are more in need of injection, are more interested in the program and consequently have longer retention time. Previous studies also noted that the type of addiction and method of drug use might affect the outcomes of the program (27). Therefore, while choosing the target groups, these characteristics have to be considered.

It is noteworthy that those people who previously used harm reduction services, like Methadone Maintenance Therapy (MMT), had shorter retention time in the program. Although it was expected that subjects using harm reduction services would be more knowledgeable and have positive viewpoints towards the program, it was reverse in the current study. As presented in the final analysis, this variable not only remained in the final model but also proved to be the strongest risk factor for quitting the program. There could be various reasons for the finding that previous harm reduction programs such as MMT were associated with lower rates of retention in the prison NEP. A plausible justification is that subjects who are on MMT may no longer require sterile injection equipment because they no longer inject drugs. Another plausible theory is that the previous negative experiences may make them less likely to participate in the prison programs; alternatively, perhaps the prison harm reduction services are poorly run, which is a probable factor affecting people's willingness to continue using it, and perhaps they had a better previous experience of programs outside prison. Therefore, ceased participating in the prison one because it does not meet the standards they have known previously. That was just the authors' speculation, and other explanations seem equally plausible but they were not considered. Type of used drugs may be another likely cause of these findings; however, further research is needed to clarify this issue.

Primary analysis showed that those who used fewer needles in a week and the HBV negative prisoners were more persistent. Hence, this idea lost its significance in the final model.

The study findings,also showed that older subjects and those with longer duration of addiction were more persistent in the program. Nonetheless, those who started injection in younger ages showed less persistent. Such differences may be the result of differences in prisoners' 
insights and awareness of the program advantages. Although the age of addiction onset was presented in final model, no significant relation between this variable and retention was observed. It seems that duration of addiction was the most effective factor and it was significant both in primary and final analyses.

To sum up, when imprisonment was considered as the base of categorization, the factors like not involving in harm reduction programs, tattooing, and longer duration of addiction were the most important factors significantly related to retention in the program. In contrast, past record of using harm reduction services was the factor that decreased persistence. It might be said that the risk of quitting the program would decrease about $68 \%$ in those not involved in harm reduction programs. It is probable that subjects who previously participated in such programs are less interested to participate again and they might show more high risk behaviors and less stability. In addition, prisoners with tattoos had history of drug injection and used more addictive drugs like ecstasy or crack.

Since both prison and prisoners' condition can affect the retention of addicted subjects in the program, the authors suggest that in order to accomplish more in the program it is needed not only to prepare the prisons condition for the program but also those prisoners involved in the program who are more likely to show retention. The current study had some limitations, which should be considered while interpreting the results; some of these limitations include short length of assessment, limited sample size, early stop of the program, and impossibility of following up participants out of the prison.

\section{Acknowledgements}

Authors wish to thank the staff of state prisons, security, and corrective measures organization of Iran for their guidance and support, especially Ms. Sepideh Alizadeh and Mr. Kayvan Shahlileh.

\section{Authors' Contributions}

Study concept and design: Mohammad Shahbazi, Marzieh Farnia, Ghobad Moradi and Mohammadreza Karamati; statistical analysis: Fatemeh Paknazar and Majid Mirmohammad Khani; analysis and interpretation of data: Majid Mirmohammad Khani and Ghobad Moradi; drafting of the manuscript: Majid Mirmohammad Khani and Ghobad Moradi; critical revision of the manuscript: Fatemeh Paknazar, Mohammad Shahbazi, Marzieh Farnia and Mohammadreza Karamati.

\section{Funding/Support}

State prisons, security and corrective measures organization of Iran.

\section{References}

1. Bruneau J, Lamothe F, Franco E, Lachance N, Desy M, Soto J, et al. High rates of HIV infection among injection drug users partici- pating in needle exchange programs in Montreal: results of a cohort study. Am J Epidemiol. 1997;146(12):994-1002.

2. Ball A, Beg M, Doupe A, Weiler GA. Evidence for Action: A critical tool for guiding policies and programmes for HIV prevention, treatment and care among injecting drug users. Int. J. Drug Policy. 2005;16(1):1-6.

3. Day C, Nassirimanesh B, Shakeshaft A, Dolan K. Patterns of drug use among a sample of drug users and injecting drug users attending a General Practice in Iran. Harm Reduct J. 2006;3:2.

4. Friedman SR, Des Jarlais DC. HIV among drug injectors: the epidemic and the response. AIDS Care.1991;3(3):239-50.

5. United Nations Programme on HIV and AIDS.. International consultation on the criminalization of HIV transmission: $31 \mathrm{Oc}$ tober-2 November 2007, Geneva, Switzerland. Joint United Nations Programme on HIV|AIDS (UNAIDS) Geneva, United Nations Development Programme (UNDP), New York, 2007. Reprod Health Matters. 2009;17(34):180-6.

6. Vlahov D, Junge B. The role of needle exchange programs in HIV prevention. Public Health Rep. 1998;113 Suppl 1:75-80.

7. Islam M, Wodak A, Conigrave KM. The effectiveness and safety of syringe vending machines as a component of needle syringe programmes in community settings. Int J Drug Policy. 2008;19(6):436-41.

8. Ray Kim W. Global epidemiology and burden of hepatitis C. Microbes Infect. 2002;4(12):1219-25.

9. Alavian $\mathrm{SM}$, Gholami B, Masarrat S. Hepatitis $\mathrm{C}$ risk factors in Iranian volunteer blood donors: a case-control study.J Gastroenterol Hepatol. 2002;17(10):1092-7.

10. Bluthenthal RN, Kral AH, Gee L, Erringer EA, Edlin BR. The effect of syringe exchange use on high-risk injection drug users: a cohort study. AIDS. 2000;14(5):605-11.

11. Des Jarlais DC, Hagan H, Friedman SR, Friedmann P, Goldberg D, Frischer M, et al. Maintaining low HIV seroprevalence in populations of injecting drug users. JAMA. 1995;274(15):1226-31.

12. Stöver H, Nelles J. Ten years of experience with needle and syringe exchange programmes in European prisons. Int. J. Drug Policy. 2003;14(5-6):437-44.

13. Heimer R. Can syringe exchange serve as a conduit to substance abuse treatment? J Subst Abuse Treat. 1998;15(3):183-91.

14. Drucker E, Lurie P, Wodak A, Alcabes P. Measuring harm reduc tion: the effects of needle and syringe exchange programs and methadone maintenance on the ecology of HIV. AIDS. 1998;12 Suppl A:S217-30.

15. MacDonald M, Law M, Kaldor J, Hales J, J. Dore G. Effectiveness of needle and syringe programmes for preventing HIV transmission. Int. J. Drug Policy. 2003;14(5-6):353-7.

16. MacDonald M, Wodak AD, Ali R, Crofts N, Cunningham PH, Dolan $\mathrm{KA}$, et al. HIV prevalence and risk behaviour in needle exchange attenders: a national study. The Collaboration of Australian Needle Exchanges. Med J Aust. 1997;166(5):237-40.

17. Vicente J, Wiessing L, Emcdda NFP, expert N. European Monitoring Centre for Drugs and Drug Addiction annual report 2007: positive assessment of HIV in IDUs though hepatitis C still very high. Euro Surveill. 2007;12(11):E071122 6.

18. Nelles J, Fuhrer A, Hirsbrunner H, Harding T. Provision of syringes: the cutting edge of harm reduction in prison? $B M J$. 1998;317(7153):270-3.

19. Gore SM, Hutchinson SJ, Cassidy J, Bird AG, Biswas S. How many drug rehabilitation places are needed in prisons to reduce the risk of bloodborne virus infection? Commun Dis Public Health. 1999;2(3):193-5.

20. Small D, Drucker E. Closed to reason: time for accountability for the International Narcotic Control Board. Harm Reduct J. 2007;4:13.

21. Jürgens R. Interventions to address HIV in prisons: Needle and syringe programmes and decontamination strategies. Geneva: World Health Organization; 2007.

22. Jurgens R, Ball A, Verster A. Interventions to reduce HIV transmission related to injecting drug use in prison. Lancet Infect Dis. 2009;9(1):57-66.

23. Chu S. Clean switch: the case for prison needle and syringe programs. HIV AIDS Policy Law Rev. 2009;14(2):5-19. 


\section{Shahbazi M et al.}

24. Eskandarieh S, Jafari F, Yazdani S, Hazrati N, Saberi-Zafarghandi MB. Compulsory Maintenance Treatment Program Amongst Iranian Injection Drug Users and Its Side Effects. Int J High Risk Behav Addict. 2014;3(4)

25. Dolan KA, Shearer J, White B, Zhou J, Kaldor J, Wodak AD. Fouryear follow-up of imprisoned male heroin users and methadone treatment: mortality, re-incarceration and hepatitis $\mathrm{C}$ infection.
Addiction. 2005;100(6):820-8.

26. Dolan K, Rutter S, Wodak AD. Prison-based syringe exchange programmes: a review of international research and development. Addiction. 2003;98(2):153-8.

27. Australian Injecting and Illicit Drug Users League.. Prison-Based Syringe Exchange Programs (PSE Programs). Canberra: AIVL; 2008. Available from: www.aivl.org.au. 